\title{
Role of MCIR variants in uveal melanoma
}

\author{
N Hearle', J Humphreys², BE Damato², R Wort', R Talaban', J Wixey', H Green', DF Easton ${ }^{3}$ and \\ RS Houlston $*, 1$
}

'Haddow Laboratories, Section of Cancer Genetics, Institute of Cancer Research, 15 Cotswold Road, Sutton SM2 5NG, UK; ${ }^{2}$ Liverpool Ocular Oncology

Centre, Royal Liverpool University Hospital, Liverpool L7 8XP, UK; ${ }^{3}$ CRUK Genetic Epidemiology Unit, University of Cambridge, Cambridge, UK

\begin{abstract}
Variants of the melanocortin-I receptor $(M C I R)$ gene have been linked to sun-sensitive skin types and hair colour, and may independently play a role in susceptibility to cutaneous melanoma. To assess the role of $M C I R$ variants in uveal melanoma, we have analysed a cohort of 350 patients for the changes within the major region of the gene displaying sequence variation. Eight variants were detected - V60L, D84E, V92M, RI5IC, II55T, RI60W, RI63Q and D294H - 63\% of these patients being hetero- or homozygous for at least one variant. Standard melanoma risk factor data were available on I 19 of the patients. MCIR variants were significantly associated with hair colour $(P=0.03)$ but not skin or eye colour. The frequency of the variants detected in the 350 patients was comparable with those in the general population, and comparison of the cumulative tumour distribution by age at diagnosis in carriers and noncarriers provided no evidence that MCIR variants confer an increased risk of uveal melanoma. We interpret the data as indicating that $M C I R$ variants do not appear to be major determinants of susceptibility to uveal melanoma. British Journal of Cancer (2003) 89, 196I - 1965. doi: 10.1038/sj.bjc.660I358 www.bjcancer.com
\end{abstract}

(c) 2003 Cancer Research UK

Keywords: $M C \mid R$; uveal melanoma

Uveal melanoma although rare is the most common primary intraocular malignancy in adults with an incidence of six per million per year (Parkin et al, 1992). Compared to cutaneous melanoma, little is known about the aetiology of the disease. Recognised risk factors for cutaneous melanoma include pale skin and fair hair, number of naevi, atypical naevi, tendency to freckle and sensitivity to sunlight (Bliss et al, 1995). While both cutaneous and uveal melanomas develop from melanocytes originating in the neural crest and also share several histological characteristics, there are distinctive differences between the two types of tumour in terms of cytogenetic anomalies and familial inheritance.

Unlike cutaneous melanoma, the genetic predisposition to uveal melanoma has not been studied extensively. While segregation of uveal melanoma and cutaneous melanoma and an association with atypical melanoma have been reported (Bataille et al, 1993; van Hees et al, 1998), most of the uveal melanomas appear to be sporadic (Lynch et al, 1968; Canning and Hungerford, 1988; Singh et al, 1996). Several studies have suggested that atypical naevi, light eye colour and exposure to ultraviolet radiation each represent independent risk factors for uveal melanoma, just as they do for cutaneous melanoma (Rootman and Gallagher, 1984; Dolin and Johnson, 1994; Bataille et al, 1995; Regan et al, 1999). The inference from these data is that genetic susceptibility to uveal melanoma is likely to be mediated through sensitivity to ultraviolet radiation.

Melanin pigmentation plays an important role in affording protection against the deleterious effects of ultraviolet radiation. In humans, $\alpha$-melanocyte-stimulating hormone $(\alpha-\mathrm{MSH})$ and other pro-opiomelanocortin peptides modulate melanin pigment formation via the melanocortin-1 receptor (MC1R) on melanocytes

\footnotetext{
*Correspondence: Dr RS Houlston; E-mail: richard.houlston@icr.ac.uk
} Revised 29 August 2003; accepted II September 2003
(Sturm et al, 2001). Two melanin pigments have been identified in humans: black eumelanin and red phaeomelanin. The relative proportions of these pigments are controlled by $\alpha-\mathrm{MSH}$ via MC1R. Eumelanin is protective, but phaeomelanin may contribute to carcinogenesis through production of free radicals (Ranadive et al, 1986; Sturm, 1998). Several point mutations in MC1R affecting function have been identified, for example, V60L, R151C, R160W, D294H, some of which have been reported to be over-represented in individuals with fair hair and skin (Valverde et al, 1995; Flanagan et al, 2000; Box et al, 2001a, b). In addition to acting as determinates of pigmentation, some variants may confer an increased risk of cutaneous melanoma (Valverde et al, 1996; Healy et al, 1999; Palmer et al, 2000). MC1R genotype has been shown to have a persisting effect on risk of cutaneous melanoma and nonmelanoma skin cancer even after adjusting for hair and skin colour, which supports the notion that MC1R may directly modulate melanocyte growth and differentiation (Valverde et al, 1996).

We have assessed the risk of uveal melanoma associated with germline $M C 1 R$ variants through sequence analysis of 350 patients and a series of 133 population controls. We have also evaluated the role of these variants as determinants of skin type, hair and eye colour, and cutaneous naevus count in 119 of the patients.

\section{PATIENTS AND METHODS}

\section{Patients}

A total of 350 unrelated patients with uveal melanoma attending the Liverpool Ocular Oncology Centre (LOOC) between 1994 and 1997 , either for treatment of a newly diagnosed tumour $(n=300)$ or for review after previous treatment $(n=50)$, were studied. In all, 
183 of the patients were male $(52 \%)$. The average age at diagnosis of uveal melanoma was 58 years (s.d. 13, range 22-89). The diagnosis of uveal melanoma was based on ophthalmoscopy and ultrasonography performed by an experienced examiner (BD) and, in patients treated by enucleation or local resection, was confirmed by histology. There was no selection of patients. The only exclusion criterion was being nonwhite.

Standard risk factors for cutaneous melanoma, propensity to sunburn, pigmentation (skin colour, hair colour at 15 years, eye colour) and number of cutaneous naevi were collected by interview and clinical examination in 119 consecutive patients aged 18-60 years. Hair colour was classified into: red, auburn, blond/fair, light brown, medium brown, dark brown and black. A three-point scale was used for eye colour, using the categories 'blue', 'green/grey' and 'hazel/brown'. Skin type was classified using an extension of Fitzpatrick's scheme (1988) as follows: type I, individuals who always burn and never tan; type II, always burn then tan slightly (mild tanning); type III, sometimes burn and always tan (moderate tanning); type IV, burn minimally and tan easily; type V, rarely burn and tan deeply; type VI, intense tanning with no burning.

Blood samples from 133 healthy spouses of colorectal cancer cases served as controls - 53 males and 80 females, mean age 56 years (s.d. 9, range 30-89). None of the controls had a personal history of malignancy. All were Caucasian and their ancestry was from the British Isles.

Blood samples and clinical data were obtained with informed consent and Local Ethical Review Board approval in accordance with the tenets of the Declaration of Helsinki.

\section{Molecular analyses}

DNA was extracted from EDTA venous blood samples using a standard sucrose lysis protocol. Detection of sequence variation in $M C 1 R$ nucleotides 107-492 was undertaken by sequencing. Two sets of overlapping primers M1F $5^{\prime}$-AGCCCGGTGCCTGGAGGTGT- $3^{\prime}$ and M1R $5^{\prime}$-TGGTAGCGCAGTGCGTAGAA- $3^{\prime}$ and M2F $5^{\prime}$-GGGAGCAAC(GA)TGCTGGAGAC- $3^{\prime}$ and M2R $5^{\prime}$ ACCGGGCGCTGCCTCTTGTG-3' ${ }^{\prime}$ were used and sequences determined using the ABI Ready Reaction Dye Terminator Cycle Sequencing Kit and ABI377 or ABI3100 semiautomated sequencers. Sequence analysis was undertaken using Sequence Navigator Software (PE Applied Biosystems, Foster City, CA, USA), and nucleotide changes identified in $M C 1 R$ were referenced to the published sequence (Genbank accession number NM_002386). The D294H variant was detected using a polymerase chain reaction restriction fragment length polymorphism. A $330 \mathrm{bp}$ fragment of
$M C 1 R$ was amplified by PCR using the primers: M3F, $5^{\prime}$ ACCATCCTGCTGGGCATTTT- $3^{\prime}$ and $5^{\prime}$-ACGGGGACCAGGGAGGTAAG- $3^{\prime}$. The PCR product was digested with TaqI in accordance with the manufacturers' recommendations (New England Biolabs Inc., Beverly, MA, USA). The G-allele (D294) is cleaved generating 150 and $180 \mathrm{bp}$ fragments cleavage whereas the A-allele $(294 \mathrm{H})$ is refractory to cleavage. Cleavage products were visualised on $2 \%$ agarose gels and digest products confirmed by sequencing. Two researchers confirmed sequence and genotyping analyses.

\section{Statistical analyses}

All statistical analyses were performed using the statistical software program STATA Version 7 (Stata Corporation 702 University Drive East, College Station, TX 77840, USA. http://www.stata.com). The distribution of categorical variables was compared by either $\chi^{2}$ or Fisher's exact test. ANOVA or $t$-test was used to test differences in the distribution of normally distributed continuous variables. Naevi counts were log transformed to normalise their distribution. Carrier and noncarrier cumulative tumour distributions by age at diagnosis were compared using log-rank test. The relationship between $M C 1 R$ genotype and risk of uveal melanoma was assessed by means of the odds ratio (OR) with $95 \%$ confidence limits calculated by unconditional logistic regression adjusting for age and sex. A test for trend $\left(P_{\text {trend }}\right)$ in increasing the risk of uveal melanoma by having more than one putative high-risk allele of $M C 1 R$ was also evaluated. Pooled estimates of the OR for this and previously published studies were obtained by calculating a weighted-average of the logarithm of ORs (Breslow and Day, 1987). Studies were weighted according to the inverse of the variance of the $\log$ of the OR. A $P$-value of 0.05 was considered statistically significant.

\section{RESULTS}

Eight variants were detected - V60L, D84E, V92M, R151C, I155T, R160W, R163Q, D294H - among the patients and controls studied (Table 1). The frequencies of combinations of $M C 1 R$ variants did not differ from expected observed allele frequencies (data not shown). Hence, the $M C 1 R$ variants can be considered as independent variants and consequently were analysed as such.

The frequencies of the $M C 1 R$ variants that have been reported in 190 UK population controls - D84E (3.5\%), V92M (17.3\%) and D294H (6.8\%) (Ichii-Jones et al, 1998) - are not statically different from that observed in the cases and controls in our study. In

Table I Relationship between MCIR variants and risk of uveal melanoma in this study

\begin{tabular}{|c|c|c|c|c|}
\hline & Cases & Controls & $\mathbf{O R}^{\mathbf{a}}$ & $95 \% \mathrm{Cl}^{\mathrm{a}}$ \\
\hline \multicolumn{5}{|c|}{ Number of MCIR variants } \\
\hline 0 & $129 / 350(36.9 \%)$ & $50 / 133(37.6 \%)$ & 1.0 & - \\
\hline Any variant & $221 / 350(63.1 \%)$ & $83 / 133(62.4 \%)$ & $1.03(1.05)$ & $0.68-1.56(0.69-1.60)$ \\
\hline \multicolumn{5}{|c|}{ Frequency of $M C I R$ variant } \\
\hline V92M & $62 / 350(17.7 \%)$ & $21 / 133(15.8 \%)$ & $1.15(1.09)$ & $0.67-1.97(0.62-1.89)$ \\
\hline RI5IC & $50 / 350(14.2 \%)$ & $19 / 133(14.4 \%)$ & $1.00(0.98)$ & $0.57-1.77(0.55-1.76)$ \\
\hline $1155 T$ & $3 / 350(0.9 \%)$ & $\mathrm{I} / \mathrm{I} 33(0.8 \%)$ & $1.14(0.75)$ & $0.12-11.07(0.07-7.52)$ \\
\hline RI60W & $48 / 350(13.7 \%)$ & $15 / 133(11.4 \%)$ & $1.16(1.23)$ & $0.63-2.13(0.66-2.29)$ \\
\hline RI63Q & $22 / 350(6.3 \%)$ & $12 / 133(9.1 \%)$ & $0.68(0.78)$ & $0.32-1.41(0.37-1.68)$ \\
\hline $\mathrm{D} 294 \mathrm{H}$ & $19 / 350(5.4 \%)$ & $4 / 133(3.0 \%)$ & $1.85(1.88)$ & $0.62-5.55(0.61-5.78)$ \\
\hline
\end{tabular}

${ }^{\mathrm{a}} \mathrm{OR}$ and $95 \% \mathrm{Cl}$ values adjusted for age and sex are given in parentheses. 
addition, the frequencies of the V60L, D84E, R151C, R160W and $\mathrm{D} 294 \mathrm{H}$ variants are not statistically different from the frequencies previously documented in the 738 individuals of Northern European ancestry reported by Vajdic et al (2003) (23.2, 2.8, $20.6,15.6$ and $6.0 \%$, respectively).

Information on hair colour, eye colour and skin type had been recorded in 119 of the patients. There was a strong relationship between skin and fair hair and eye colour $(P<0.05)$. The relationship between these three phenotypes and $M C 1 R$ variation is detailed in Table 2. No significant association was seen between possession of one or more $M C 1 R$ variants and eye colour $(P=0.46)$. Similarly, no significant relationship was seen between skin type and possession of a $M C 1 R$ variant $(P=0.29)$ or naevus count $(P=0.45)$. There was, however, an association between $M C 1 R$ status and hair colour with an over-representation of variants in individuals with light or red hair $(P=0.03)$.

The frequency of each of the $M C 1 R$ variants in the 350 patients was not statistically different from that observed in the controls. Of the 350 patients studied, 129 (36.9\%) had no MC1R variants, 154 (44.0\%) had one $M C 1 R$ variant and 67 (19.1\%) possessed two or more variants.

The mean ages at diagnosis in noncarriers and carriers of one and two or more of $M C 1 R$ variants in our study were not significantly different -57.9 , s.d. $14 ; 58.0$, s.d. 13 and 58.0, s.d. 12 , respectively; $P=0.99$. Similarly, the cumulative distributions of age at diagnosis in carriers of one and two or more variants, and noncarriers were not significantly different.

Two research groups have previously reported on the relationship between MC1R variants and risk of uveal melanoma Metzelaar-Blok et al (2001) based on analysis of 162 patients and Vajdic et al (2003) based on analysis of 62 patients. In both studies, there was no difference in the frequency of variants in cases compared to controls. Table 3 summarises the results from these two studies. Also shown are pooled estimates of the risk of uveal melanoma based on all studies for individual variants and one, two or more and any $M C 1 R$ variant. In pooling studies, there was no evidence of heterogeneity. No statistically significant associations between risk and MC1R status were detected in this analysis.

\section{DISCUSSION}

We performed this study to determine whether germline $M C 1 R$ variants confer an increased risk of uveal melanoma. Our investigation was prompted by the observation that patients with uveal melanomas have a greater number of cutaneous naevi than that of the general population, and that numbers of cutaneous naevi, as well as skin and hair colour, are a function of $M C 1 R$ genotype (Bataille et al, 1995).

The frequency of $M C 1 R$ variants detected in patients in our study was not significantly different from the frequencies in the general population, and were very similar to estimates obtained in unselected North-European populations. Furthermore, we found that the age at diagnosis of uveal melanoma in carriers of $M C 1 R$ variants was not significantly different from noncarriers. These findings imply that $M C 1 R$ variants are unlikely to confer an increased risk of uveal melanoma. The main strengths of our study are the large number of patients in our sample and correlation of $M C 1 R$ variants with age at diagnosis, a factor that has not previously been investigated.

In our study, we detected eight $M C 1 R$ variants: V60L, D84E V92M, R151C, I155T, R160H, R163Q and D294H. Linkage disequilibrium has been reported to exist between certain variants (Palmer et al, 2000). In our study this was nondetectable; however, our study was not empowered to explore this. Previous studies have demonstrated a relationship between $M C 1 R$ variants and hair and skin type, notably a strong association between the R151C, $\mathrm{R} 160 \mathrm{Q}$ and $\mathrm{R} 294 \mathrm{H}$ variants, with fair skin and red hair (Valverde et al, 1995; Palmer et al, 2000; Bastiaens et al, 2001). Collectively, the $M C 1 R$ variants we detected were over-represented in the patients with light skin and red or fair hair, in keeping with these previous observations. The relationship was, however, less pronounced than in some previous studies, largely because of the small number of patients with red or auburn hair and type I skin type in our study.

Most, but not all, previous studies have shown that $M C 1 R$ variants are associated with an increased risk of both cutaneous melanoma (Valverde et al, 1996; Palmer et al, 2000) and nonmelanoma skin cancers (Box et al, 2001a,b). There is some

Table 2 Numbers of homo- and heterozygotes for MCIR alleles in patients according to skin type, and hair and eye colour

\begin{tabular}{|c|c|c|c|c|c|c|c|c|c|}
\hline \multirow[b]{2}{*}{ Phenotype } & \multicolumn{9}{|c|}{$M C I R$ variant $^{\mathrm{a}}$} \\
\hline & V60L & D84E & V92M & RI5IC & II55T & RI60W & RI63Q & D294H & Combined \\
\hline \multicolumn{10}{|l|}{ Skin type } \\
\hline $1(n=13)$ & I & I & 3 & 2 & 0 & 2 & 3 & 2 & 10 \\
\hline$\|(n=38)$ & 6 & 0 & 7 & 7 & 0 & 11 & 2 & 2 & 26 \\
\hline III $(n=29)$ & 7 & 0 & 6 & 3 & 0 & 5 & 2 & । & 20 \\
\hline $\mathrm{IV}(n=25)$ & 3 & 1 & 8 & 3 & 0 & 3 & I & 1 & 16 \\
\hline \multicolumn{10}{|l|}{ Hair colour } \\
\hline $\operatorname{Red}(n=2)$ & 0 & 1 & 0 & 0 & 0 & 0 & 0 & I & 2 \\
\hline Auburn $(n=7)$ & 2 & 0 & 0 & I & 0 & 3 & I & 2 & 6 \\
\hline Blond $(n=16)$ & 2 & 0 & 3 & 8 & 0 & 3 & 2 & 2 & 15 \\
\hline Light brown $(n=26)$ & 3 & 0 & 7 & 1 & 0 & 4 & 1 & 1 & 14 \\
\hline Medium brown $(n=20)$ & 4 & 0 & 7 & 2 & 0 & 4 & 0 & 0 & 14 \\
\hline Blue $(n=68)$ & 10 & 0 & 17 & 11 & 0 & 8 & 5 & 3 & 44 \\
\hline Green-grey $(n=12)$ & 2 & 0 & 2 & 0 & 0 & 4 & 0 & I & 7 \\
\hline Hazel-brown $(n=39)$ & 9 & 3 & 7 & 5 & 0 & 9 & 3 & 2 & 28 \\
\hline
\end{tabular}

${ }^{a}$ Compound heterozygotes appear in more than one column under the analysis of individual alleles, but only once in the combined column. Thus, the "combined" column does not necessarily represent the sum of values for the individual alleles. 
Table 3 Estimates of risk of uveal melanoma associated with MCIR variants in this and published studies and meta-analyses of studies

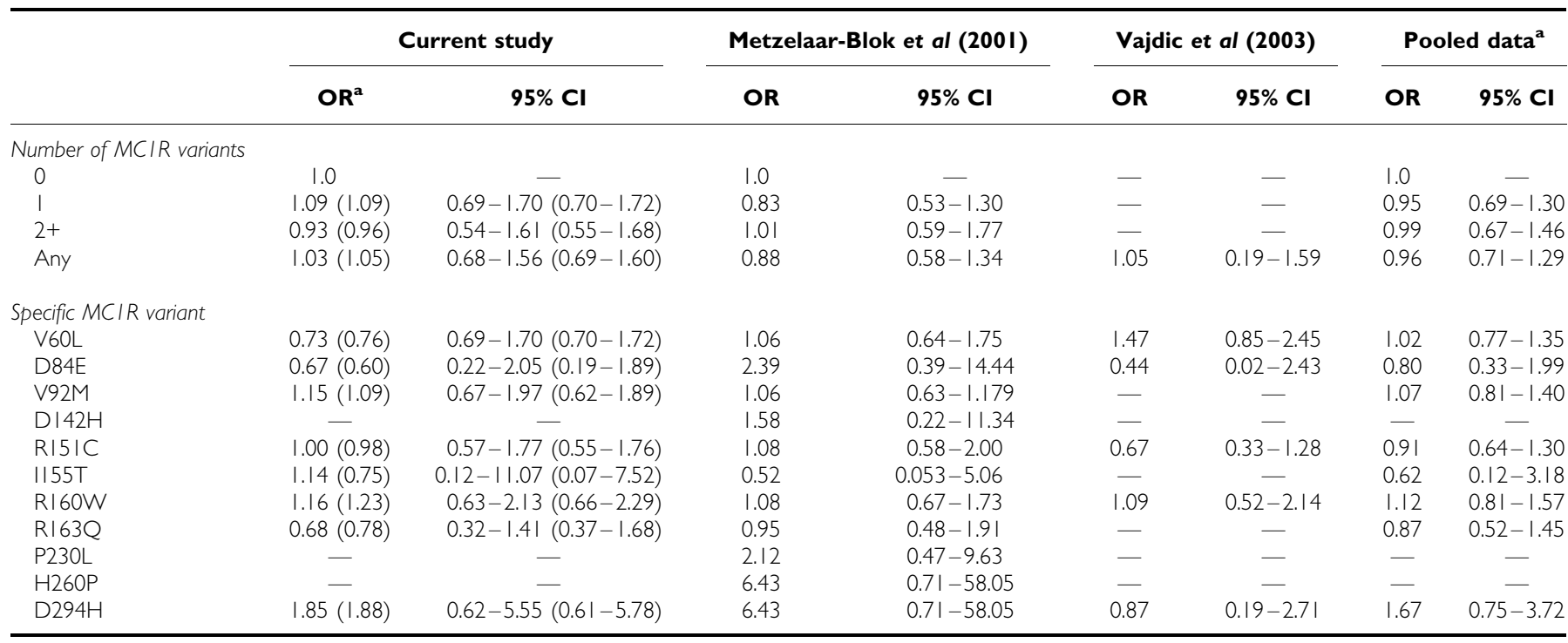

a Based on pooling adjusted estimates from the current study.

evidence that this effect persists even after correcting for skin type. This suggests that certain $M C 1 R$ variants can exert an effect on melanoma tumorigenesis in a dual manner, both as a determinant of fair skin and as a component in an independent additional pathway (Palmer et al, 2000; Van der Velden et al, 2001).

Our data support the findings of Metzelaar-Blok et al (2001) and the recent study reported by Vajdic et al (2003), who found no relationship between variation in $M C 1 R$ and risk of uveal melanoma. Moreover, pooling data from all three studies provide no evidence that variants confer an increased risk of uveal melanoma. We cannot, however, exclude the possibility that variants confer very small increases in risk of $\sim 1$.1-fold.

In our study, the majority of patients had blue eyes in keeping with the finding of Regan et al (1999), who reported that uveal melanoma is more common in individuals with light irises, suggesting that increased sensitivity to sunlight from prolonged ultraviolet exposure represents a risk factor. Hence, our findings do not necessarily contradict the observation that ultraviolet radiation and pigmentation probably represent risk factors for uveal melanoma. However, in contrast to cutaneous melanoma, most of the patients with uveal melanomas in our study and other reports (Metzelaar-Blok et al, 2001) do not have type I or type II skin.

\section{REFERENCES}

Bastiaens MT, ter Huurne JA, Kielich C, Gruis NA, Westendorp RG, Vermeer BJ, Bavinck JN (2001) Melanocortin-1 receptor gene variants determine the risk of nonmelanoma skin cancer independently of fair skin and red hair. Am J Hum Genet 68: 884-894

Bataille V, Pinney E, Hungerford JL, Cuzick J, Bishop DT, Newton JA (1993) Five cases of coexisting primary ocular and cutaneous melanoma. Arch Dermatol 129: 198-201

Bataille V, Sasieni P, Cusick J, Hungerford JL, Swerdlow A, Newton-Bishop JA (1995) Risk of ocular melanoma in relationship to cutaneous and iris naevi. Int J Cancer 60: 622-626

Bliss JM, Ford D, Swerdlow AJ, Armstrong BK, Cristofolini M, Elwood JM, Green A, Holly EA, Mack T, MacKie RM, Osterlind RM, Walter SD, Peto J, Easton D for the International Melanoma Analysis Group (IMAGE) (1995) Risk of cutaneous melanoma associated with pigmenta-
Although of a common embryological origin, there are several biological differences between uveal, conjunctival and cutaneous melanocytes (Sarna, 1992). Firstly, there is no evidence that ultraviolet light initiates melanogenesis in uveal melanomas (Sahm et al, 2001). Secondly, it is unclear whether uveal melanocytes continue to synthesise melanin in adulthood ( $\mathrm{Hu}$ et al, 1995). Lastly, whereas epidermal melanocytes synthesise melanosomes and export these to keratinocytes, melanosomes within uveal melanocytes remain relatively inactive (Boissy, 1988). These differences may explain at least in part why incidence rates of uveal melanoma do not show such geographical differences to those seen in cutaneous melanoma. Moreover, differences in the relative importance of aetiological factors between the two tumour types are reflected at the molecular level - activating mutations of $B R A F$ are almost universal in cutaneous melanomas but not in uveal tumours (Davies et al, 2002; Cohen et al, 2003; Edmunds et al, 2003).

\section{ACKNOWLEDGEMENTS}

We are grateful to the patients who participated in this study. Funding for this work was undertaken with support from Cancer Research UK. Douglas Easton is a Principal Research Fellow of Cancer Research UK. tion characteristics and freckling: systematic overview of 10 casecontrol studies. The International Melanoma Analysis Group (IMAGE). Int J Cancer 62: 367 - 376

Boissy RE (1988) The melanocyte. Its structure, function, and subpopulations in skin, eyes, and hair. Dermatol Clin 6: $161-173$

Box NF, Duffy DL, Chen W, Stark M, Martin NG, Sturm RA, Hayward NK. (2001a) MC1R genotype modifies risk of melanoma in families segregating CDKN2A mutations. Am J Hum Genet 69: 765-773

Box NF, Duffy DL, Irving RE, Russell A, Chen W, Griffyths LR, Parsons PG, Green AC, Sturm RA (2001b) Melanocortin-1 receptor genotype is a risk factor for basal and squamous cell carcinoma. J Invest Dermatol 116: $224-229$

Breslow NE, Day NE (1987) Statistical Methods in Cancer Research, Vol 1 and 2. Lyon: IARC 
Canning CR, Hungerford J (1988) Familial uveal melanoma. Br J Ophthal 72: $241-243$

Cohen Y, Goldenberg-Cohen N, Parrella P, Chowers I, Merbs SL, Pe'er J, Sidransky D (2003) Lack of BRAF mutation in primary uveal melanoma. Invest Ophthalmol Vis Sci 44: $2876-2878$

Davies H, Bignell GR, Cox C, Stephens P, Edkins S, Clegg S, Teague J, Woffendin H, Garnett MJ, Bottomley W, Davis N, Dicks E, Ewing R, Floyd Y, Gray K, Hall S, Hawes R, Hughes J, Kosmidou V, Menzies A, Mould C, Parker A, Stevens C, Watt S, Hooper S, Wilson R, Jayatilake H, Gusterson BA, Cooper C, Shipley J, Hargrave D, Pritchard-Jones K, Maitland N, Chenevix-Trench G, Riggins GJ, Bigner DD, Palmieri G, Cossu A, Flanagan A, Nicholson A, Ho JW, Leung SY, Yuen ST, Weber BL, Seigler HF, Darrow TL, Paterson H, Marais R, Marshall CJ, Wooster R, Stratton MR, Futreal PA (2002) Mutations of the BRAF gene in human cancer. Nature 417: 949 - 954

Dolin PJ, Johnson GJ (1994) Solar ultraviolet radiation and ocular disease: a review of the epidemiological and experimental evidence. Ophthalmic Epidemiol 1: $155-164$

Edmunds SC, Cree IA, Di Nicolantonio F, Hungerford JL, Hurren JS, Kelsell DP (2003) Absence of BRAF gene mutations in uveal melanomas in contrast to cutaneous melanomas. Br I Cancer 88: 1403-1405

Fitzpatrick TB (1988) The validity and practicality of sun-reactive skin types I through VI. Arch Dermatol 124: 869-871

Flanagan N, Healy E, Ray A, Philips S, Todd C, Jackson IJ, Birch-Machin MA, Rees JL (2000) Pleiotropic effects of the melanocortin-1 receptor (MC1R) gene on human pigmentation. Hum Mol Genet 9: $2531-2537$

Healy E, Todd C, Jackson IJ, Birch-Machin M, Rees JL (1999) Skin type, melanoma, and melanocortin 1 receptor variants. J Invest Dermatol 112: $512-513$

Hu DN, McCormick SA, Orlow SJ, Rosemblat S, Lin AY, Wo K (1995) Melanogenesis by human uveal melanocytes in vitro. Invest Ophthalmol Vis Sci 36: $931-938$

Ichii-Jones F, Lear JT, Heagerty AH, Smith AG, Hutchinson PE, Osborne J, Bowers B, Jones PW, Davies E, Ollier WE, Thomson W, Yengi L, Bath J, Fryer AA, Strange RC (1998) Susceptibility to melanoma: influence of skin type and polymorphism in the melanocyte stimulating hormone receptor gene. J Invest Dermatol 111: 218-221

Lynch HT, Anderson DE, Krush AJ (1968) Heredity and intraocular malignant melanoma. Study of two families and review of forty-five cases. Cancer 21: 119-125

Metzelaar-Blok JA, ter Huurne JA, Hurks HM, Keunen JE, Jager MJ, Gruis NA (2001) Characterization of melanocortin-1 receptor gene variants in uveal melanoma patients. Invest Ophthalmol Vis Sci 42: 1951-1954
Palmer JS, Duffy DL, Box NF, Aitken JF, O'Gorman LE, Green AC, Hayward NK, Martin NG, Sturm RA (2000) Melanocortin-1 receptor polymorphisms and risk of melanoma: is the association explained solely by pigmentation phenotype? Am J Hum Genet 66: 176-186

Parkin DM, Muir CS, Whelan LB (1992) Cancer Incidence in Five Countries, Vol VI. Lyon: International Agency for Research on Cancer

Ranadive NS, Shirwadkar S, Persad S, Menon IA (1986) Effects of melanininduced free radicals on the isolated rat peritoneal mast cells. J Invest Dermatol 86: $303-307$

Regan S, Judge HE, Gragoudas ES, Egan KM (1999) Iris color as a prognostic factor in ocular melanoma. Arch Ophthalmol 117: $811-814$

Rootman J, Gallagher RP (1984) Color as a risk factor in iris melanoma. Am J Ophthalmol 98: $558-561$

Sahm M, Loeffler KU, Seifert P, Spitznas M (2001) Effect of ultraviolet radiation on melanogenesis in four different types of cultured bovine ocular pigmented cells. Graefes Arch Clin Exp Ophthalmol 239: 302-309

Sarna T (1992) Properties and function of the ocular melanin - a photobiophysical view. J Photochem Photobiol B 12: 215-258

Singh AD, Shields CL, De Potter P, Shields JA, Trock B, Cater J, Pastore D (1996) Familial uveal melanoma. Clinical observations on 56 patients. Arch Ophthalmol 114: 392-399

Sturm RA (1998) Human pigmentation genes and their response to solar UV radiation. Mutat Res 422: 69-76

Sturm RA, Teasdale RD, Box NF (2001) Human pigmentation genes: identification, structure and consequences of polymorphic variation. Gene 277: $49-62$

Vajdic C, Kricker A, Duffy DL, Aitken JF, Stark M, Huurne JA, Martin NG, Armstrong BK, Hayward NK (2003) Ocular melanoma is not associated with CDKN2A or MC1R variants - a population-based study. Melanoma Res 13: 409-413

Valverde P, Healy E, Jackson I, Rees JL, Thody AJ (1995) Variants of the melanocyte-stimulating hormone receptor gene are associated with red hair and fair skin in humans. Nat Genet 11: 328-330

Valverde P, Healy E, Sikkink S, Haldane F, Thody AJ, Carothers A, Jackson IJ, Rees JL (1996) The Asp84Glu variant of the melanocortin-1 receptor (MC1R) is associated with melanoma. Hum Mol Genet 5: 1663-1666

van der Velden PA, Sandkuijl LA, Bergman W, Pavel S, van Mourik L, Frants RR, Gruis NA (2001) Melanocortin-1 receptor variant R151C modifies melanoma risk in Dutch families with melanoma. Am J Hum Genet 69: $774-779$

van Hees CL, Jager MJ, Bleeker JC, Kemme H, Bergman W (1998) Occurrence of cutaneous and uveal melanoma in patients with uveal melanoma and their first degree relatives. Melanoma Res 8: 175-180 